\title{
EFECTO DEL EXTRACTO ETANÓLICO DE MACA (Lepidium meyenii Walp) SOBRE LOS NIVELES DE TESTOSTERONA Y EL CONTEO DE ESPERMATOZOIDES DE RATONES MACHOS
}

\author{
Walter Félix De la Cruz Ramírez ${ }^{1}$, Jorge Arroyo Acevedo ${ }^{2}$ \\ 1. Profesor de Farmacología, Universidad Peruana Cayetano Heredia, Lima, Perú. \\ 2. Profesor de Farmacología, Universidad Nacional Mayor de San Marcos, Lima, Perú.
}

\section{RESUMEN}

Objetivos: Determinar el efecto del extracto etanólico de maca sobre la concentración de testosterona y el conteo de espermatozoides de ratones machos jóvenes. Material y métodos: Ratones machos Balb-C53 fueron repartidos aleatoriamente en dos grupos: uno experimental, que recibió $2 \mathrm{~g} / \mathrm{kg}$ de peso corporal de extracto etanólico de maca por vía oral durante 14 días y otro control, que recibió placebo. En cada ratón se determinó el peso corporal, el peso de los órganos reproductivos, la concentración sérica de testosterona y el conteo de espermatozoides. Resultados: El peso corporal y el peso de los testículos y epidídimos no fueron afectados por el tratamiento con extracto etanólico de maca. El peso de las vesículas seminales en los ratones del grupo experimental fue mayor que en el grupo control (35,09 $\pm 7,70$ vs. $26,19 \pm 7,00 \mathrm{mg} ; \mathrm{p}=0,007)$. La concentración sérica de testosterona de los animales tratados con maca fue mayor que en el grupo control $(6,96 \pm 1,91$ vs. $0,31 \pm 0,36 \mathrm{ng} / \mathrm{dl} ; \mathrm{p}=0,000001)$. El conteo de espermatozoides en los ratones del grupo experimental fue mayor que en los controles $(282,42 \pm 104,58$ vs. $187,00 \pm 57,06$ millones de células $/ \mathrm{ml}$, respectivamente; $p=0,011)$. Conclusión: El extracto etanólico de maca en dosis de $2 \mathrm{~g} / \mathrm{kg}$ de peso corporal indujo el aumento de los niveles séricos de testosterona y del conteo de espermatozoides en ratones machos jóvenes.

Palabras Clave: Lepidium, Espermatogénesis, Testosterona. (fuente: DeCS BIREME)

\section{EFFECTS OF ETHANOL EXTRACT OF MACA (Lepidium meyenii Walp) ON SERUM TESTOSTERONE LEVELS AND SPERM COUNT OF MALE MICE}

\begin{abstract}
Objective: To determine the effect of ethanol extract of maca on the concentration of testosterone and sperm count of young male mice. Material and methods: Male mice Balb-C53 were randomized into two groups: experimental, which received $2 \mathrm{~g} / \mathrm{kg}$ body weight ethanolic extract of maca orally for 14 days and a control group that received only placebo. In each mouse was determined the body weight reproductive organ weights, serum testosterone and sperm count. Results: Body weight and weight of the testes and epididymides were not affected by treatment with ethanolic extract of maca. The weight of seminal vesicles in mice in the experimental group was higher than in the control group $(35,09 \pm 7,70$ vs. $26,19 \pm 7,00 \mathrm{mg} ; \mathrm{p}=0,007)$. Serum testosterone treated animals was higher than in the control group (6,96 \pm $1,91$ vs. $0,31 \pm 0,36 \mathrm{ng} / \mathrm{dL} ; \mathrm{p}=0,000001)$. The sperm count in mice in the experimental group was higher than in controls (282,42 $\pm 104,58 \mathrm{vs}$. $187,00 \pm 57,06$ million cells $/ \mathrm{mL}$ respectively; $\mathrm{p}=0,011$ ). Conclusions: Ethanolic extract of maca at dose of $2 \mathrm{~g} / \mathrm{kg}$ of body weight induced increased serum levels of testosterone and sperm count in young male mice.
\end{abstract}

Key words: Lepidium, Spermatogenesis, Testosterone. (source: MeSH NLM).

\section{INTRODUCCIÓN}

Lepidium meyenii Walp. (Maca) es una planta de la familia Brassicaceae, oriunda de los andes centrales de Perú que crece entre los 4000 y $4500 \mathrm{~m}$ sobre el nivel del mar ${ }^{[1]}$. Fue domesticada hace más de 2000 años y su uso prosiguió durante la época colonial hasta la actualidad con la creencia tradicional de que puede mejorar la fertilidad y la actividad sexual de humanos y animales domésticos ${ }^{(1-3)}$.

En los últimos años, diversas investigaciones farmacológicas experimentales en animales y humanos han demostrado que la maca puede tener propiedades afrodisíacas (4-7) $y^{y}$ efectos estimulantes sobre la espermatogénesis ${ }^{(8-15)}$.

Sin embargo, hasta el momento no se han identificado los principios activos de la maca que estarían implicados en sus supuestas propiedades terapéuticas y además hay controversias acerca del efecto de la maca sobre las hormonas sexuales como la testosterona y la progesterona.

Tomando en cuenta estos antecedentes, se realizó esta investigación con el objetivo de determinar los efectos del extracto etanólico de maca sobre la concentración de testosterona y el conteo de espermatozoides de ratones machos jóvenes.

\section{MATERIAL Y MÉTODOS}

\section{ANIMALES DE EXPERIMENTACIÓN}

Se utilizaron 24 ratones machos jóvenes de la cepa BalbC53, de 30 días de edad, de 19-26 g de peso corporal, sometidos a cuarentena previa y sin apareamiento. Estos ratones fueron obtenidos del Instituto Nacional de Salud (INS) en Lima, Perú. 
Durante el periodo de investigación, los ratones fueron alojados en un bioterio, donde se mantuvieron bajo condiciones estandarizadas de: temperatura ambiental: 18 $\pm 2 \stackrel{\circ}{\circ}$, humedad: $60 \%$ y guardando un foto periodo de 12 horas de luz y 12 de oscuridad. La dieta fue sobre la base de un alimento comercial balanceado de la marca Purina ${ }^{\circledR}$ y agua a voluntad.

\section{PREPARACIÓN DEL EXTRACTO ETANÓLICO DE LEPIDUMIUM MEYENII WALP. (MACA)}

Los hipocotilos de la maca fueron obtenidos en Carhuamayo, Junin a $4500 \mathrm{~m}$ sobre el nivel del mar. La identidad de la planta fue autenticada según el sistema de Clasificación de Cronquist por un especialista en Botánica del Museo de Historia Natural de la Universidad Nacional Mayor de San Marcos.

La maca del ecotipo amarillo fue secada a una temperatura menor a $40{ }^{\circ} \mathrm{C}$ y luego molida hasta obtener partículas pequeñas y homogéneas los cuales fueron sometidos a maceración en alcohol de $96 \%$ por 8 días. Finalizado este tiempo se filtro y obtuvo el extracto etanólico por evaporación del solvente a una temperatura menor a $40^{\circ} \mathrm{C}$. $15 \mathrm{~g}$ del extracto seco fue disuelto en $150 \mathrm{~mL}$ de agua destilada para preparar una solución de $100 \mathrm{mg} / \mathrm{mL}$ el cual fue colocado en un frasco y mantenidos en refrigerador a 4 oC hasta uso.

\section{DISEÑO EXPERIMENTAL}

Se empleó un diseño experimental, con dos grupos seleccionados al azar y con observaciones sólo después del tratamiento. Los animales fueron asignados aleatoriamente a 2 grupos: uno experimental, que recibió 2 $\mathrm{g} / \mathrm{kg}$ de peso corporal (pc) de extracto etanólico de maca durante 14 días y otro control, que recibió placebo. El placebo consistió en el mismo vehículo en el que se diluyó el extracto etanólico de maca. El extracto y el placebo fueron administrados por vía oral usando jeringas de $1 \mathrm{~mL}$ provistas de una cánula de intubación oro-esofágica № 18 .

Al final de los 14 días de tratamiento, los ratones fueron anestesiados con cloroformo a una concentración de 1,479 $\mathrm{g} / \mathrm{mL}$ a $20{ }^{\circ} \mathrm{C}$ y luego sacrificados por decapitación. Inmediatamente después de la decapitación se obtuvo una muestra sanguínea la que fue depositada en viales para el respectivo análisis de hormonas.

\section{MEDICIÓN DEL PESO CORPORAL}

Los ratones fueron pesados a los 7 y 14 días después del inicio del tratamiento en una balanza analítica previamente calibrada, las mediciones se expresaron en gramos.

\section{CONCENTRACIÓN SÉRICA DE TESTOSTERONA}

La muestra de sangre obtenida después de la decapitación, se centrifugó inmediatamente para separar el suero, y luego proseguir con la medición de la concentración sérica de testosterona por inmunoanálisis. Todas las muestras se analizaron en un mismo ensayo para evitar variaciones entre los análisis. Los datos se expresaron en ng/dL.

\section{MEDICIÓN DEL PESO DE ÓRGANOS REPRODUCTIVOS}

Después del sacrificio de los animales, de acuerdo a lo descrito por Chung et al. ${ }^{(12)}$; los testículos, epidídimos y vesículas seminales, se disecaron cuidadosamente limpiándolos de las adherencias de tejido conectivo y graso, y posteriormente fueron pesados en una balanza de precisión, expresándose las mediciones en mg.

\section{CONTEO DE ESPERMATOZOIDES DEL EPIDÍDIMO}

El conteo espermático se realizó tal como lo describen Sobarzo y Bustos-Obregón (16). Para ello, uno de los epidídimos fue homogeneizados en $2 \mathrm{~mL}$ de suero salino ( $\mathrm{NaCl} 0,9 \%$ ) y luego mantenido en refrigeración a $4 \stackrel{\circ}{\mathrm{C}}$ por 24 horas para permitir que los espermatozoides se desprendan de las paredes. Una alícuota se colocó en una cámara de Neubauer hemocitométrica para el conteo de los espermatozoides en los 25 cuadrados centrales. Posteriormente, se calculó el número de espermatozoide por mililitro de suspensión. Sólo se contaron espermatozoides con cabeza y cola y los resultados fueron expresados como millones de células $/ \mathrm{mL}$. Se contaron los espermatozoides de la cabeza, cuerpo y cola de un epidídimo.

\section{ANÁLISIS ESTADÍSTICO}

Las variables analizadas fueron las siguientes: peso corporal, peso de los órganos reproductivos, concentración sérica de Testosterona y conteo espermático.

La asociación entre la variable dependiente categórica y las variables independientes continuas con distribución normal fueron evaluadas usando la prueba de t-student y cuando se trató de variables independientes sin distribución normal fueron evaluadas usando la prueba $U$ de Mann-Whitney. En todos los casos se consideró estadísticamente significativo un valor de $p<0,05$. Para todos los cálculos se utilizó el programa SPSS Ver. 11.0.

\section{RESULTADOS}

\section{PESO CORPORAL}

No se observaron diferencias significativas entre el peso corporal de los ratones del grupo experimental y control antes del tratamiento con extracto etanólico de maca y a los siete y 14 días después del inicio del tratamiento $(p=0,10$; $\mathrm{p}=0,51$ y $\mathrm{p}=0,18$ respectivamente) (Figura 1 ). 
Figura 1. Efecto de la maca sobre el peso corporal de

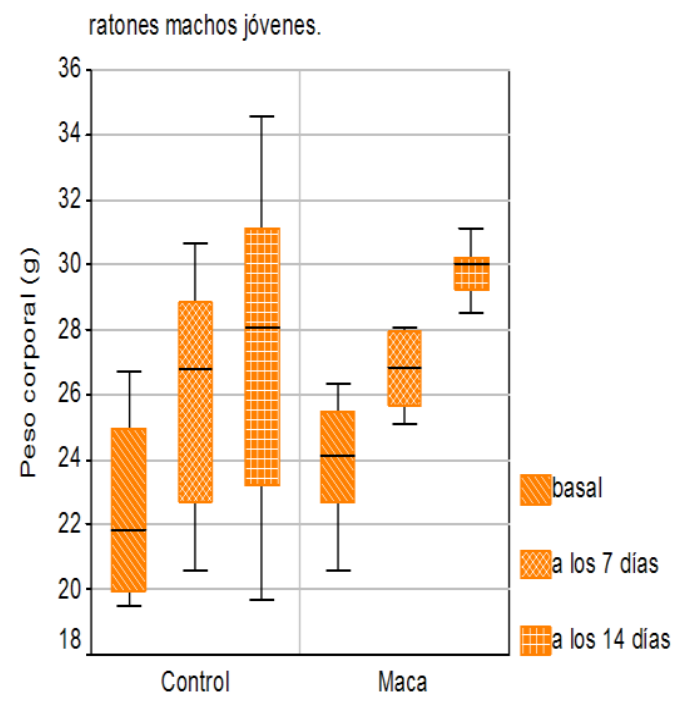

\section{PESO DE ÓRGANOS REPRODUCTIVOS}

El peso de los testículos y los epidídimos al final de los 14 días de tratamiento con maca fueron similares en ambos grupos ( $p=0,39$ y $p=0,22$ respectivamente) [Figura 2].

El peso de la vesículas seminales de los ratones tratados con extracto etanólico de maca $(35,09 \pm 7,70 \mathrm{mg})$ fue mayor al observado en los ratones del grupo control $(26,19 \pm 7,00$ $\mathrm{mg} ; \mathrm{p}=0,007$ ) [Figura 2].

Figura 2. Efecto de la maca sobre el peso de los órganos

sexuales de ratones machos jóvenes.

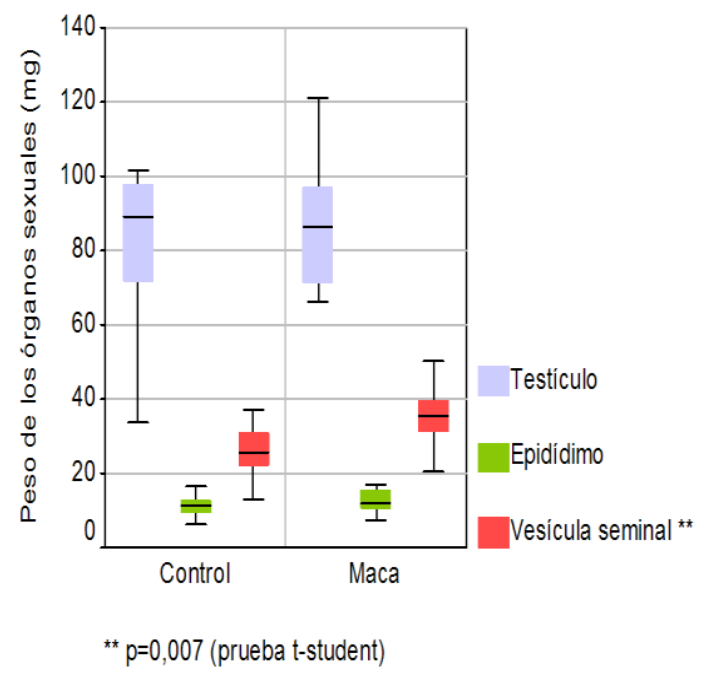

\section{CONCENTRACIÓN SÉRICA DE TESTOSTERONA}

Después de 14 días de tratamiento, la concentración sérica de testosterona de los ratones del grupo experimental $(6,96$ $\pm 1,91 \mathrm{ng} / \mathrm{dL}$ ) fue significativamente mayor al observado en los ratones del grupo control $(0,31 \pm 0,36 \mathrm{ng} / \mathrm{dL} ; \mathrm{p}<0,000001)$ [Figura 3].

Figura 3. Efecto de la maca sobre la concentración de testosterona de ratones machos jóvenes.

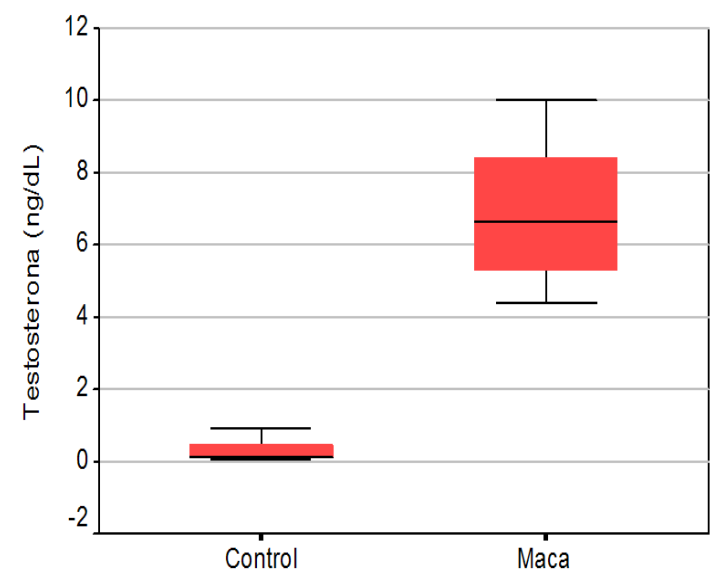

$p<0,001$ (prueba U de Mann-Whitney)

\section{CONTEO DE ESPERMATOZOIDES DEL EPIDÍDIMO}

En los ratones tratados con extracto etanólico de maca durante 14 días, se observó un incremento significativo del conteo de espermatozoides del epidídimo con respecto al grupo control $(282,42 \pm 104,58$ vs $187,00 \pm 57,06$ millones de células $/ \mathrm{mL}$, respectivamente; $p=0,011$ ) (Figura 4).

Figura 4. Efecto de la maca sobre el conteo espermático

de ratones machos jóvenes.

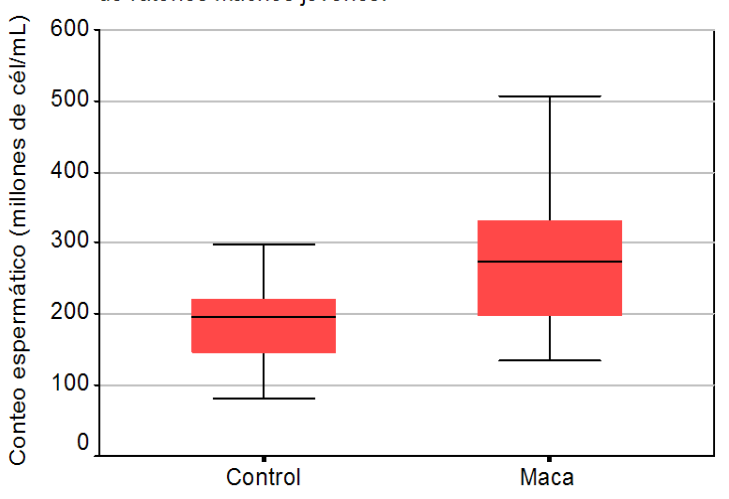

$p=0,011$ (prueba t-student) 


\section{DISCUSIÓN}

Los epidídimos y las vesículas seminales son órganos reproductivos andrógeno dependientes (12). Los estudios disponibles hasta el momento, reportan hallazgos contradictorios sobre el efecto de la maca en el peso de

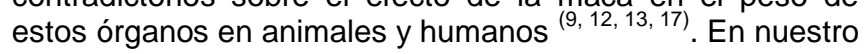
estudio se encontró que el peso de las vesículas seminales fue mayor en los ratones tratados con extracto etanólico de maca. Estudios con dietas a base de isoflavonas han demostrado que las vesículas seminales son los órganos más sensibles al estímulo de la testosterona ${ }^{(18)}$. Gonzales GF (19) observó lo mismo en hombres tratados con clomifeno. Estas observaciones sugieren que el extracto etanólico de maca tiene efectos androgénicos sobre el peso de las vesículas seminales; sin embargo, es necesario realizar mayores estudios para explicar este efecto de la maca.

En este trabajo, se ha observado un incremento significativo de los niveles séricos de testosterona en los ratones machos jóvenes tratados con extracto etanólico de maca. Similares resultados han sido hallados por Oshima et al. ${ }^{(20)}$ en ratones machos de tres semanas de edad, tratados con maca cruda durante 30 días.

Por su parte Gonzales et al. (11) reportaron que ratas expuestas agudamente a grandes altitudes y tratadas con extracto acuoso de maca presentaron aumento de la concentración de testosterona a los 7 días de tratamiento. Estos mismos autores encuentran que a nivel del mar, ratas tratadas con maca presentaron incremento de los niveles testosterona a los 14 días de tratamiento. Chung et al. ${ }^{(12)}$, encontraron que ratas tratadas con $1 \mathrm{~g} / \mathrm{kg}$ pc de extracto acuoso maca presentaban mayor concentración sérica de testosterona que las tratadas con $0,1 \mathrm{~g} / \mathrm{kg} \mathrm{pc}$. En otro estudio, Gonzales et al. ${ }^{[17]}$ encontraron que las ratas tratadas con maca amarilla tenían mayor concentración de testosterona que las tratadas con maca negra. Finalmente otro estudio (15) encontró que los niveles de 17hidroxiprogesterona eran mayores en hombres tratados con $3 \mathrm{~g}$ de maca a las 2 semanas de tratamiento.

Estas observaciones son opuestas a lo reportado en otras investigaciones donde hombres tratados con maca pulverizada en tabletas ${ }^{(7,8)}$ y ratas machos de 3 y 4 meses de edad tratados con extractos alcohólicos y acuosos de maca ${ }^{[10,13]}$, no presentaron cambios significativos en la concentración sérica de testosterona y estradiol.

Los niveles crecientes de testosterona en sangre pueden ser atribuibles a los efectos sinérgicos de varios componentes de la maca, tales como aminoácidos, esteroles, vitaminas y otros ${ }^{(1)}$. Oshima et al. ${ }^{(20)}$ creen que el aumento de la concentración sérica de testosterona y progesterona en ratones tratados con maca podría deberse a la acción indirecta de sus saponinas. Teniendo en cuenta estos antecedentes y los hallazgos del presente estudio se puede inferir que los niveles séricos de testosterona habrían aumentado debido a la acción indirecta y sinérgica de los diferentes constituyentes químicos presentes en el extracto etanólico de maca.

Al igual que en otras investigaciones en hombres ${ }^{(8)}$ y ratas machos ${ }^{(9-14)}$, en el presente estudio, se observó un incremento significativo del conteo de espermatozoides en los ratones tratados con extracto etanólico maca. El aumento del conteo espermático se correlaciona con el mayor tiempo de duración de las etapas de la espermatogénesis donde se produce la espermiación y la mitosis de la espermatogonia (8-14). Una adecuada concentración de testosterona es necesaria para completar la espermatogénesis ${ }^{[21]}$, ello explicaría que en el presente estudio el incremento de la concentración sérica de testosterona en los ratones tratados con maca se haya asociado a un aumento de su conteo espermático.

Si bien el efecto del extracto etanólico de maca sobre el peso de las vesículas seminales y la espermatogénesis, observado en este y otros estudios, pueden deberse a sus efectos sobre la concentración de hormonas sexuales (testosterona), queda la posibilidad de que los extractos de maca contengan compuestos semejantes a los andrógenos, capaces de ligarse a receptores humanos y promover la trascripción regulada por señales de hormonas esteroideas. Sin embargo, Bogani et al. (22) demostraron que varios extractos de maca (obtenidos con diversos solventes: metanol, etanol, hexano y cloroformo) no pudieron regular la activación de los elementos de respuesta a glucocorticoides (ERG).

En conclusión, el tratamiento diario con extracto etanólico de maca en dosis de $2 \mathrm{~g} / \mathrm{kg}$ pc por vía oral durante 14 días incremento los niveles de testosterona en los ratones machos jóvenes y este efecto se asoció al aumento significativo del peso de las vesículas seminales y el conteo de espermatozoides del epidídimo.

\section{Correspondencia:}

Walter De la Cruz

Dirección: Calle Hipólito Unánue 124, San Miguel, Lima, Perú.

Teléfono: 452-2164

Correo electrónico: wafedera@yahoo.com

\section{REFERENCIAS BIBLIOGRÁFICAS}

1 Balick MJ, Lee R. Maca: from traditional food crop to energy andlibido stimulant. Altern Ther Health Med. 2002; 8:96-8.

2 Obregón L. Maca. Planta medicinal y nutritiva del Perú. 1ra ed. Lima: Instituto de Fitoterapia Americano; 1998.

3 Chacon G. La maca (Lepidium peruvianum sp. Nov.) y su hábitat. Rev Peru Biol. 1990; 3:171-2.

4 Zheng BL, He K, Kim CH, Rogers L, Shao Y, Huang ZY, et al. Effect of a lipidic extract from Lepidium meyenii on sexual behavior in mice and rats. Urology 2000; 55:598-602. 
5 Cicero AFG, Bandieri E, Arletti R. Lepidium meyenii Walp4 improves sexual behaviour in male rats independently from its action on spontaneous locomotor activity. J Ethnopharmacol. 2001; 75:225-9.

6 Cicero AFG, Piacente S, Plaza A, Sala E, Arletti R, Pizza C. Hexanic Maca extract improves rat sexual performance moits effectively than methanolic and chloroformic Maca extracts. Andrologia 2002; 34:177-9.

7 Gonzales GF, Cordova A, Vega K, Chung A, Villena A, Góñez C, Castillo S. Effect of Lepidium meyenii (Maca) on sexual desire and its absent relationship with serum testosterone levels in adult healthy men. Andrologia 20087 34:367-72.

8 Gonzales GF, Cordova A, Gonzales C, Cheng A, Vega K, Villena A. Lepidium meyenii (Maca) improved semeri parameters in adult men. Asian J Androl. 2001; 3:301-3.

9 Gonzales GF, Ruiz A, Gonzales C, Villegas L, Cordova A. Effect of Lepidium meyenii (Maca) roots on spermatogenesis of male rats. Asian J Androl. 2001; 3:231-3.

10 Gonzales GF, Rubio J, Chung A, Gasco M, Villegas L. Effect of alcoholic extract of Lepidium meyenii (Maca) on testicular function in male rats. Asian J Androl. 2003; 5:349-52.

11 Gonzales GF, Gasco M, Córdova A, Chung A, Rubio J, Villegas L. Effect of Lepidium meyenii (Maca) on spermatogenesis in male rats acutely exposed to high altituctat (4340 m). J Endocrinol. 2004; 180:87-95.

12 Chung F, Rubio J, Gonzales C, Gasco M, Gonzales GE2 Dose-response effects of Lepidium meyenii (Maca) aqueous extract on testicular function and weight of different organs in adult rats. J Ethnopharmacol. 2005; 98:143-7.

13 Gonzales C, Rubio J, Gasco M, Nieto J, Yucra S, Gonzales GF. Effect of short-term and long-term treatments with three ecotypes of Lepidium meyenii (Maca) on spermatogenesis in rats. J Ethnopharmacol. 2006; 103:448-54.
Gonzales GF, Córdova A, Vega K, Chung A, Villena A and Góñez C. Effect of Lepidium meyenii (Maca), a root with aphrodisiac and fertility-enhancing properties, on serum reproductive hormone levels in adult healthy men. J Endocrinol. 2003; 176:163-8.

Bustos-Obregon E, Yucra S, Gonzales GF. Lepidium meyenii (Maca) reduces spermatogenic damage induced by a single dose of malathion in mice. Asian J Androl. 2005; 7:71-6.

Sobarzo C, Bustos-Obregón E. Sperm quality in mice acutely treated with parathion. Asian J Androl. 2000; 2:147-50.

Gonzales GF, Miranda S, Nieto J, Fernández G, Yucra S, Rubio J, et al. Red Maca (Lepidium meyenii) reduced prostate size in rats. Reprod Biol Endocrinol. 2005; 3:5.

Stroheker T, Cabaton N, Berges R, Lamothe V, Lhuguenot JC, Chagnon MC. Influence of dietary soy isoflavones on the accessory sex organs of the Wistar rat. Food Chem Toxicol. 2003; 41:1175-83.

Gonzales GF. Basal serum testosterone as an indicator of response to clomiphene treatment in human epididymis, seminal vesicles and prostate. Andrologia 2002; 34:308-16.

Oshima M, Gu Y, Tsukada S. Effects of Lepidium meyenii Walp and Jatropha macrantha on blood levels of estradios$17 \beta$, progesterone, testosterone and the rate of embryo implantation in mice. J Vet Med Sci. 2003; 65:1145-6.

Gonzales G. Andrología. Fertilidad e infertilidad. 1 ra ed. Lima: Ediciones Instituto de Investigación de la Altura; 1992.

Bogani P, Simonini F, Iriti M, Rossoni M, Faoro F, Poletti A, Visioli F. Lepidium meyenii (Maca) does not exert direct androgenic activities. J Ethnopharmacol. 2006; 104:415-7.

Recibido: 10/01/2012

Aceptado para publicación: 24/02/2012 